\title{
Caracterização de Isolados de Phytophthora drechsleri, Agente Causal da Podridão Mole de Raízes de Mandioca
}

\author{
Maria de Fátima S. Muniz ${ }^{1}$, Flávia Waleska R. de Andrade', Fátima M. Queiroz², \\ Gilson Moura Filho ${ }^{3}$ \& Maria Menezes ${ }^{4}$
}

\begin{abstract}
${ }^{1}$ Departamento de Fitotecnia e Fitossanidade, Universidade Federal de Alagoas, CEP 57100-000, Rio Largo, AL, e-mail: muniz@cenargem.embrapa.br; ${ }^{2}$ Diretoria de Pesquisa Agropecuária e Pesqueira/SEAP, CEP 57020-050, Maceió, AL, e-mail: fm-queiroz@uol.com.br; ${ }^{3}$ Departamento de Solos, Engenharia e Economia Rural, Universidade Federal de Alagoas, CEP 57100-000, Rio Largo, AL; ${ }^{4}$ Departamento de Agronomia - Fitossanidade, Universidade Federal Rural de Pernambuco, CEP 52171-900, Recife, PE
\end{abstract}

(Aceito para publicação em 16/01/2006)

Autor para correspondência: Fátima Maria Queiroz

MUNIZ, M. F. S., ANDRADE, F. W. R., QUEIROZ, F. M., MOURA FILHO, G. \& MENEZES, M. Caracterização de isolados de Phytophthora drechsleri, agente causal da podridão mole de raízes de mandioca. Fitopatologia Brasileira 31:195-198. 2006.

\section{RESUMO}

O presente trabalho teve como objetivo caracterizar nove isolados de Phytophthora sp. obtidos de mandioca (Manihot esculenta), através da morfologia e morfometria das estruturas propagativas e crescimento micelial em diferentes temperaturas e avaliar sua patogenicidade. Os esporângios produzidos em extrato de solo não esterilizado mostraram-se ovóides, não papilados, persistentes, formados em esporangióforos não ramificados ou em simpódio, com dimensões de 24,6 - 57,4 $\mu \mathrm{m}$ x 14,8 - 37,7 $\mu \mathrm{m}$ e relação comprimento/largura de 1,0 - 2,6. Os clamidósporos foram raros. Os oósporos obtidos em cultura monospórica em V8 ágar eram apleuróticos, com 13,1 - 34,4 $\mu \mathrm{m}$ de diâmetro. Oogônios mostraram-se esféricos e mediram 19,7 - 41,0 $\mu \mathrm{m}$ de diâmetro; anterídios anfígenos, com dimensões de 8,2 - 24,6 $\mu \mathrm{m}$ x 8,2 - 19,7 $\mu \mathrm{m}$. O maior diâmetro das colônias ocorreu a $25^{\circ} \mathrm{C}$ em V8 ágar. Os isolados patogênicos às plantas e raízes destacadas de mandioca inoculados foram identificados como Phytophthora drechsleri.

Palavras-chave adicionais: taxonomia, Manihot esculenta.

\begin{abstract}
Characterization of Phytophthora drechsleri, the causal agent of cassava soft root rot

Nine Phytophthora isolates from cassava (Manihot esculenta) were characterized based on morphology and morphometry of propagative structures, growth at $10,15,20,25,30$ and $35{ }^{\circ} \mathrm{C}$, and by evaluating its pathogenicity. Sporangia produced on nonsterile soil extract were ovoid, nonpapillate and persistent, formed in a sympodium or unbranched sporangiophores, 24.6 to $57.4 \mu \mathrm{m}$ long x 14.8 to $37.7 \mu \mathrm{m}$ wide, and length-breadth ratio was $1.0-2.6$. Chlamydospores were rarely observed. Oospores produced in single spore culture on V8 agar medium were aplerotic, and 13.1 to $34.4 \mu \mathrm{m}$ in diameter. Antheridia were amphigynous, measuring $8.2-24.6 \mu \mathrm{m} \times 8.2-19.7 \mu \mathrm{m}$; oogonia ranged from 19.7 to $41.0 \mu \mathrm{m}$ in diameter. Culture growth was greatest at $25^{\circ} \mathrm{C}$ in V8 agar medium. The isolates that were pathogenic to plants and detached roots of cassava were identified as Phytophthora drechsleri Tucker.
\end{abstract}

Additional keywords: taxonomy, Manihot esculenta.

As doenças mais importantes da mandioca (Manihot esculenta Crantz) são aquelas que afetam a qualidade sanitária do material de plantio, as podridões radiculares e as deteriorações de pós-colheita. Dentre estas, as podridões radiculares de pré ou pós-colheita são as mais importantes para a cultura (Lozano, 1989).

No Brasil, a podridão mole de raízes de mandioca é causada principalmente por Phytophthora drechsleri Tucker (Figueiredo \& Albuquerque, 1970; Lima et al., 1993; Poltronieri et al., 1993). No Estado do Pará, Poltronieri et al. $(1993 ; 1997)$ identificaram, além de $P$. drechsleri, $P$. nicotianae Breda de Haan (=P. parasitica Dastur), $P$. richardiae Buisman e Pythium scleroteichum Drechsler.
Face à importância da cultura da mandioca para o Estado de Alagoas e considerando que a podridão radicular vem comprometendo a sua sobrevivência, este trabalho teve como objetivo caracterizar isolados de Phytophthora sp. associados à enfermidade, através da morfologia, morfometria e crescimento em meio de cultura sob diferentes temperaturas, assim como avaliar a patogenicidade dos isolados.

O trabalho foi conduzido no Laboratório de Fitopatologia do Centro de Ciências Agrárias da Universidade Federal de Alagoas, em Rio Largo, Alagoas.

Raízes e caules de plantas de mandioca com sintomas de podridão foram coletados no campo (Tabela 1), colocados 
M.F.S. Muniz et al.

TABELA 1 - Informações sobre os isolados de Phytophthora sp. obtidos de mandioca (Manihot esculenta) no Estado de Alagoas

\begin{tabular}{lcccc}
\hline Código do isolado & Cultivar & Parte afetada & Município & Data do isolamento \\
\hline M1 & Preta e Branca & Raiz & Santana do Mundaú & $04 / 07 / 2002$ \\
M2 & Rosinha & Raiz & Santana do Mundaú & $04 / 07 / 2002$ \\
M3 & Rosinha & Raiz & Branquinha & $15 / 07 / 2002$ \\
M11 & Platina & Caule & Chã Preta & $30 / 07 / 2002$ \\
M13 & Cariri & Caule & São Sebastião & $23 / 07 / 2003$ \\
M14 & $*$ NI & Raiz & São Sebastião & $23 / 07 / 2003$ \\
M16 & Campinas & Caule & Feira Grande & $02 / 09 / 2003$ \\
M17 & Cariri & Raiz & São Sebastião & $16 / 10 / 2003$ \\
M18 & Platina & Raiz & São Sebastião & $16 / 10 / 2003$ \\
\hline
\end{tabular}

*NI= não identificada

individualmente em sacos de plástico e transportados ao Laboratório de Fitopatologia. As partes afetadas foram lavadas com água corrente para remover o solo. Segmentos dos tecidos apodrecidos foram lavados em álcool etílico $70 \%$ e secos sobre papel - toalha. Fragmentos foram transferidos para placas de Petri contendo o meio de cultura batata-dextrose-ágar (BDA) com inibidores seletivos - 10 ppm de benomil, 25 ppm de nistatina, 25 ppm de PCNB, $10 \mathrm{ppm}$ de rifampicina e $10 \mathrm{ppm}$ de ampicilina (Masago et al., 1977). As culturas foram incubadas a $25^{\circ} \mathrm{C}$ no escuro e examinadas diariamente durante uma semana, procurandose observar o aparecimento de Phytophthora sp.

As colônias que se desenvolveram a partir dos tecidos infectados foram transferidas para placas de Petri contendo meio de BDA e, posteriormente, preservadas em água destilada esterilizada (Castellani, 1967), e mantidas a temperatura ambiente, para os estudos posteriores.

Estacas de mandioca da cultivar Rosinha, medindo de 8-10 cm de comprimento, com 2-3 gemas foram plantadas na posição vertical em copos de plástico $(500 \mathrm{~mL})$ contendo solo autoclavado $\left(120^{\circ} \mathrm{C}\right.$ por $\left.2 \mathrm{~h}\right)$. A inoculação foi efetuada 40 dias após o plantio, utilizando-se nove plantas para cada isolado. O inóculo foi constituído por discos de BDA incubado no escuro, à $25^{\circ} \mathrm{C}$, retirados da margem da colônia de cada isolado contendo micélio em crescimento ativo, os quais foram inseridos em pequenas incisões, realizadas com auxílio de bisturi, localizadas na base do caule, com aproximadamente $5 \mathrm{~mm}$ de extensão e $1 \mathrm{~mm}$ de profundidade. As testemunhas receberam discos do meio de BDA, utilizando-se a mesma metodologia. As plantas inoculadas e as testemunhas foram mantidas em câmara úmida, consistindo de sacos de plásticos previamente umedecidos com água destilada, por $48 \mathrm{~h}$, sob condições ambiente. A avaliação foi realizada oito dias após a inoculação, através da contagem do número de plantas mortas pelos isolados do patógeno.

Raízes de mandioca da cv. Rosinha foram coletadas no campo, lavadas em água corrente e desinfestadas em solução de hipoclorito de sódio 3\%, durante 10 min. A seguir, foram lavadas em água destilada esterilizada e secas com papeltoalha, utilizando-se nove raízes/isolado. A inoculação foi efetuada conforme Poltronieri et al. (2001). Com o auxílio de um vasador de rolhas (5 $\mathrm{mm}$ de diâmetro) foram feitos dois orifícios próximos às extremidades das raízes, onde foi depositado um disco de micélio do patógeno crescido em meio de BDA, no escuro, à temperatura de $25^{\circ} \mathrm{C}$. Em seguida, os orifícios foram fechados com a porção da raiz removida e o local da inoculação envolvido com algodão umedecido e coberto com filme de PVC. As raízes testemunhas sofreram o mesmo processo, porém receberam apenas disco do meio de BDA. Posteriormente, as raízes inoculadas e as testemunhas foram acondicionadas em sacos de plásticos e mantidas no ambiente. A avaliação foi realizada sete dias após a inoculação, efetuando-se a contagem do número de raízes com sintomas de podridão.

O reisolamento do patógeno foi efetuado a partir dos tecidos afetados das plantas e das raízes de mandioca, empregando-se o meio basal (BDA) com inibidores seletivos, conforme citado anteriormente.

Os isolados foram identificados com base na morfologia da colônia, temperatura mínima, máxima e ótima para o crescimento vegetativo, e a produção, morfologia e dimensões dos esporângios, clamidósporos, oogônios, oósporos e anterídios, segundo as descrições apresentadas por Ho (1981).

As medições das estruturas foram realizadas em lâminas preparadas com água destilada esterilizada, empregando-se um microscópio equipado com micrômetro ocular. Foram efetuadas 50 medições/ estrutura/isolado.

Discos de micélio (5 mm de diâmetro) de cada isolado retirados da margem de colônias cultivadas em BDA a $25{ }^{\circ} \mathrm{C}$ por três dias, foram transferidos para o centro de placas de Petri (um disco por placa de $9 \mathrm{~cm}$ de diâmetro) contendo $20 \mathrm{~mL}$ do meio V8 ágar (200 mL de suco V8; $3 \mathrm{~g}$ de $\mathrm{CaCO}_{3} ; 17$ g de ágar e $800 \mathrm{~mL}$ de água destilada). 
A incubação foi a $10,15,20,25,30$ e $35{ }^{\circ} \mathrm{C}$ no escuro, durante cinco dias, quando foi medido o diâmetro da colônia, em dois sentidos diametralmente opostos, com o auxílio de uma régua milimetrada, e observada a morfologia da colônia de cada isolado. O delineamento experimental foi o inteiramente ao acaso em esquema fatorial (isolados $\mathrm{x}$ temperaturas) com cinco repetições, sendo cada uma constituída por uma placa.

Para a produção dos esporângios e clamidósporos, discos de micélio (5 mm de diâmetro) provenientes da margem da colônia de cada isolado com quatro dias de cultivo no meio V8 ágar foram transferidos para placas contendo aproximadamente $10 \mathrm{~mL}$ de extrato de solo não esterilizado preparado conforme Pratt (1981). Igual quantidade de solo e água destilada foram misturados formando uma suspensão, permanecendo durante $24 \mathrm{~h}$ sem agitação. Após este período, a suspensão foi filtrada através de uma camada dupla de papel filtro. O período de incubação foi de $48 \mathrm{~h}$ a $25^{\circ} \mathrm{C}$, em condições de alternância luminosa (12 h luz/12 h escuro).

Para a produção das estruturas sexuais, os isolados foram inicialmente testados para homotalismo. Discos de micélio (5 mm de diâmetro) foram transferidos para o centro de placas de Petri contendo o meio V8 ágar. Após cinco dias a $25^{\circ} \mathrm{C}$, sob luz alternada ( $12 \mathrm{~h} \mathrm{luz} / 12 \mathrm{~h}$ escuro), as culturas foram observadas ao microscópio para visualização dos oósporos.

Todos os isolados foram patogênicos quando inoculados em plantas e raízes de mandioca da cultivar Rosinha. Plantas inoculadas apresentaram inicialmente lesões necróticas no caule, evoluindo para murcha e morte. Verificou-se que aos oito dias da inoculação, o percentual de plantas mortas/isolado variou de 55\% a 65\%. Nas raízes, os sintomas de podridão foram evidentes aos sete dias da inoculação. Plantas e raízes testemunhas permaneceram sadias. Culturas reisoladas a partir das plantas e raízes inoculadas foram semelhantes às originais, confirmando-se o Postulado de Koch.
$\mathrm{O}$ isolado e a temperatura influenciaram o crescimento micelial de Phytophthora sp. Verificou-se, a 5\% de probabilidade, interação significativa entre os fatores isolados e temperaturas. Diante disso, observou-se que o crescimento micelial do patógeno variou nas temperaturas em cada isolado testado (Tabela 2). A $10{ }^{\circ} \mathrm{C}$, verificou-se apenas traço de crescimento micelial, sendo que o maior diâmetro das colônias ocorreu a $25^{\circ} \mathrm{C}$ (Tabela 2). A $35^{\circ} \mathrm{C}$ houve crescimento apenas nos isolados M1, M3, M11, M13, M14 e M16. Klisiewicz (1977) trabalhando com $P$. drechsleri de cártamo (Carthamus tinctorius L.), constatou que o patógeno cresce numa ampla faixa de temperatura, de $6-36{ }^{\circ} \mathrm{C}$, sendo a temperatura ótima entre 24 e $30{ }^{\circ} \mathrm{C}$, estando os dados obtidos neste trabalho, dentro dos referidos intervalos. Os isolados obtidos apresentaram colônias com aspecto cotonoso no meio V8 ágar.

Com relação à produção e morfologia das estruturas assexuais e sexuais, os esporângios formados em extrato de solo eram de formato ovóide, não papilados, persistentes, originados em esporangióforos não ramificados ou em simpódio, com dimensões que variaram de $24,6-57,4 \mu \mathrm{m}$ x 14,8 - 37,7 $\mu \mathrm{m}(\bar{X}=42,9$ x 27,0 $\mu \mathrm{m})$, apresentando uma relação comprimento/largura de 1: 2,6 ( $\bar{X}=1,6)$ (Tabela 3). Observou-se a liberação de zoósporos.

Raros clamidósporos observados em alguns isolados apresentaram-se globosos e terminais. Segundo Cother \& Griffin (1974), estes propágulos são registrados apenas em alguns isolados de $P$. drechsleri.

Numerosos oogônios foram produzidos em monocultura em meio V8 ágar, medindo $18,0-34,4 \mu \mathrm{m}$ de diâmetro. Oósporos mostraram-se apleuróticos, com 19,7 $-41,0 \mu \mathrm{m}$ de diâmetro $(\bar{X}=28,6 \mu \mathrm{m})$; anterídios anfígenos, unicelulares, com dimensões de 8,2 - 24,6 x 8,2 - 19,7 $\mu \mathrm{m}$ $(\bar{X}=16,3 \times 15,1 \mu \mathrm{m})$ (Tabela 3$)$.

A comparação das médias das estruturas propagativas e o crescimento dos isolados a $35{ }^{\circ} \mathrm{C}$, estão de acordo com

TABELA 2 - Médias do crescimento micelial (cm) de nove isolados de Phytophthora sp. obtidos de mandioca (Manihot esculenta), no meio V8 ágar em diferentes temperaturas

\begin{tabular}{|c|c|c|c|c|c|c|c|}
\hline \multirow[b]{2}{*}{ Isolados } & \multicolumn{7}{|c|}{ Temperaturas ${ }^{\circ} \mathrm{C}$} \\
\hline & 10 & 15 & 20 & 25 & 30 & 35 & Médias \\
\hline M1 & 0 & $2,6 \mathrm{C} \mathrm{bcd}$ & $5,8 \mathrm{Bab}$ & $7,2 \mathrm{Ab}$ & $5,0 \mathrm{Bc}$ & 1,7 Dd & $3,7 \mathrm{bcd}$ \\
\hline M2 & 0 & $2,3 \mathrm{Cd}$ & $5,6 \mathrm{Bab}$ & $7,2 \mathrm{Ab}$ & 7,1 Aa & $0 \mathrm{De}$ & $3,7 \mathrm{bcd}$ \\
\hline M3 & 0 & 2,4 Ecd & $5,8 \mathrm{Bab}$ & $6,9 \mathrm{Ab}$ & $4,9 \mathrm{Cc}$ & $3,8 \mathrm{Db}$ & $4,0 \mathrm{~b}$ \\
\hline M11 & 0 & $2,4 \mathrm{Cd}$ & $4,9 \mathrm{Bb}$ & $6,7 \mathrm{Ab}$ & $6,1 \mathrm{Ab}$ & $2,0 \mathrm{Ccd}$ & 3,7 bcd \\
\hline M13 & 0 & $3,6 \mathrm{Da}$ & $5,9 \mathrm{Ca}$ & $8,9 \mathrm{Aa}$ & $7,8 \mathrm{Ba}$ & $3,0 \mathrm{Dbc}$ & $4,9 \mathrm{a}$ \\
\hline M14 & 0 & 3,6 Dab & $5,7 \mathrm{Cab}$ & $8,4 \mathrm{Aa}$ & 7,1 Bab & $6,1 \mathrm{Ca}$ & $5,2 \mathrm{a}$ \\
\hline M16 & 0 & 3,4 Dab & $5,9 \mathrm{Bab}$ & $8,4 \mathrm{Aa}$ & $4,5 \mathrm{Cc}$ & $1,3 \mathrm{Ed}$ & $3,9 \mathrm{bc}$ \\
\hline M17 & 0 & $2,4 \mathrm{Ccd}$ & $5,6 \mathrm{Bab}$ & $8,3 \mathrm{Aa}$ & $5,0 \mathrm{Bc}$ & $0 \mathrm{De}$ & $3,6 \mathrm{~cd}$ \\
\hline M18 & 0 & 3,4 Cabc & $5,4 \mathrm{Bab}$ & $8,7 \mathrm{Aa}$ & $3,5 \mathrm{Cd}$ & $0 \mathrm{De}$ & $3,5 \mathrm{~d}$ \\
\hline Médias & 0 & $2,9 \mathrm{C}$ & $5,6 \mathrm{~B}$ & $7,8 \mathrm{~A}$ & $5,7 \mathrm{~B}$ & $2,0 \mathrm{D}$ & \\
\hline
\end{tabular}

Médias de cinco repetições;

Médias seguidas pela mesma letra maiúscula, nas linhas, e minúsculas, nas colunas, não diferem entreentre si, pelo teste de Tukey, a 5\% de probabilidade. 
M.F.S. Muniz et al.

TABELA 3 - Tamanho médio das estruturas propagativas de isolados de Phytophthora sp. obtidos de mandioca (Manihot esculenta) no Estado de Alagoas

\begin{tabular}{|c|c|c|c|c|c|c|c|}
\hline \multirow[b]{2}{*}{ Isolado } & \multicolumn{3}{|c|}{ Esporângio $(\mu \mathrm{m})^{1}$} & \multirow{2}{*}{$\begin{array}{c}\text { Oogônio } \\
(\mu \mathrm{m})^{1}\end{array}$} & \multirow{2}{*}{$\begin{array}{c}\text { Oósporo } \\
(\mu \mathrm{m})^{1}\end{array}$} & \multicolumn{2}{|c|}{ Anterídio $(\mu \mathrm{m})^{1}$} \\
\hline & Comp. (C) & Larg. (L) & $\mathrm{C} / \mathrm{L}$ & & & $\begin{array}{l}\text { Comp. } \\
\text { (C) }\end{array}$ & $\begin{array}{l}\text { Larg. } \\
\text { (L) }\end{array}$ \\
\hline M1 & 46,4 & 27,4 & 1,7 & 27,0 & 22,2 & 15,5 & 14,6 \\
\hline M2 & 45,0 & 27,9 & 1,6 & 28,4 & 23,1 & 16,0 & 14,3 \\
\hline M3 & 44,7 & 28,9 & 1,6 & 27,3 & 22,6 & 16,5 & 15,5 \\
\hline M11 & 39,4 & 22,6 & 1,8 & 29,9 & 25,7 & 15,0 & 13,6 \\
\hline M13 & 33,8 & 21,6 & 1,6 & 30,2 & 24,6 & 17,0 & 15,9 \\
\hline M14 & 45,8 & 28,9 & 1,6 & 28,0 & 22,8 & 16,4 & 15,4 \\
\hline M16 & 42,8 & 28,2 & 1,5 & 31,8 & 26,9 & 15,8 & 15,2 \\
\hline M17 & 45,9 & 29,6 & 1,6 & 27,9 & 22,7 & 17,1 & 15,9 \\
\hline M18 & 42,3 & 27,6 & 1,5 & 27,1 & 22,0 & 17,6 & 15,6 \\
\hline Média & 42,9 & 27,0 & 1,6 & 28,6 & 23,6 & 16,3 & 15,1 \\
\hline $\begin{array}{l}\text { Desvio } \\
\text { padrão }\end{array}$ & 4,07 & 2,86 & 0,09 & 1,65 & 1,71 & 0,83 & 0,78 \\
\hline C.V $(\%)$ & 9,5 & 10,6 & 5,8 & 5,8 & 7,3 & 5,1 & 5,2 \\
\hline $\mathrm{I}^{2}$ & $30-50$ & - & $1,6-1,9$ & $<35$ & - & $12-20$ & - \\
\hline
\end{tabular}

${ }^{1}$ Médias de 50 medições de cada estrutura propagativa/isolado;

${ }^{2}$ Medidas indicadas para a espécie em Ho (1981).

os intervalos da chave proposta por Ho (1981) para a espécie P. drechsleri Tucker.

\section{REFERÊNCIAS BIBLIOGRÁFICAS}

CASTELLANI, A. Maintenance and cultivation of the common pathogenic fungi of man in sterile distilled water. Further researches. Journal of Tropical Medicine and Hygiene 70:181-184. 1967.

COTHER, E.J. \& GRIFFIN, D.M. Chlamydospore germination in Phytophthora drechsleri. Transactions British Mycological Society 61:273-279. 1974.

FIGUEIREDO, M.M. \& ALBUQUERQUE, F.C. Podridão mole das raízes da mandioca (Manihot esculenta). Pesquisa Agropecuária Brasileira 5:389-393. 1970.

HO, H.H. Synoptic keys to the species of Phytophthora. Mycologia 73:705-714. 1981.

KLISIEWICZ, J.M. Identity and relative pathogenicity of some heterothallic Phytophthora species associated with root and stem rot of safflower. Phytopathology 67:1174-1177. 1977.

LIMA, M.F., REIFSCHNEIDER, F.J.B., TAKATSU, A. \& FONSECA, M.E.N. Caracterização de isolados de Phytophthora de mandioca. Fitopatologia Brasileira 18:416-424. 1993.

LOZANO, J.C. Outbreaks of cassava diseases and losses induced. Fitopatologia Brasileira 14:7-11. 1989.

MASAGO, H., YOSHIKAWA, M., FUKADA, M. \& NAKANISHI, N. Selective inhibition of Pythium spp. on a medium for direct isolation of Phytophthora spp. from soils and plants. Phytopathology 67:425-428. 1977.

POLTRONIERI, L.S., TRINDADE, D.R. \& SILVA, H.M. Podridão mole de raízes de mandioca induzida por Phytophthora drechsleri e Phytophthora nicotianae var. parasitica no Estado do Pará. Fitopatologia Brasileira 18:282. 1993. (Resumo).

POLTRONIERI, L.S., TRINDADE, D.R., SILVA, H.M. \& ALBUQUERQUE, F.C. Patógenos associados a podridão mole de raízes de mandioca no estado do Pará. Fitopatologia Brasileira 22:111. 1997.

POLTRONIERI, L.S., ALBUQUERQUE, F.C., TRINDADE, D. R., DUARTE, M.L.R. \& BENCHIMOL, R.L. Podridão mole das raízes de mandioca. In: Luz, E.D.M.N., Santos, A.F., Matsuoka, K. \& Bezerra, J.L. (Eds.) Doenças causadas por Phytophthora no Brasil. Campinas. Livraria e Editora Rural. 2001. pp. 433-454.

PRATT, R.G. Morphology, pathogenicity, and host range of Phytophthora megasperma, P. erythroseptica, and P. parasitica from arrowleaf clover. Phytopathology 71:276-282. 1981. 